\title{
Effects of ampicillin, ceftriaxone, chloramphenicol, pefloxacin and trimethoprim-sulphamethoxazole on Salmonella typhi within human monocyte-derived macrophages
}

\author{
Heman R. Chang*, Ion-Rusan Vladoianu and Jean-Claude Pechère \\ Department of Microbiology, University of Geneva Medical School, C.M.U., 9, av de \\ Champel, 1211 Geneva 4, Switzerland
}

\begin{abstract}
The killing effect of various antimicrobial agents used in the therapy of Salmonella typhi infection was tested against Salm. typhi strain Ty2 after phagocytosis by human monocyte-derived macrophages. The macrophages, cultured in 96-well microtitre plates, were infected for $1 \mathrm{~h}$ at $37^{\circ} \mathrm{C}$ by opsonized Salm. typhi Ty2 at a bacteria-cell ratio of $9: 1$. When added to the infected macrophage monolayers, at one and ten times the MIC, ampicillin, ceftriaxone and pefloxacin appeared to be highly bactericidal ( $<0-25 \log _{10}$ cfu/well after $20 \mathrm{~h}$, against $4 \log _{10}$ cfu/well in antibiotic-free controls). Trimethoprim-sulphamethoxazole was bactericidal at ten times the MIC, but not at the MIC. Chloramphenicol was mostly bacteriostatic at the concentrations tested. As a control, gentamicin $(10 \mathrm{mg} / \mathrm{l})$ did not exhibit any significant antibacterial effect, indicating that most or all the bacteria recovered from lysed cells were intracellular. Other controls for phagocytosis were also performed with heat-killed Candida albicans. Our results seem to correlate with the known clinical effect of some antimicrobials in human Salm. typhi infection. The in-vitro assay described here may be useful for assessing the activity of antimicrobial agents against Salm. typhi infection.
\end{abstract}

\section{Introduction}

Typhoid fever is still a major public health problem associated with significant morbidity and mortality in many countries (Edelman \& Levine, 1986). Since Salmonella typhi is a pathogen confined to humans, no suitable animal model is available for testing the therapeutic efficacy of potential treatments for this disease. Salmonella sp. are capable of entering cells and lie within the phagolysosomes of the host cells in an acidic environment (Carrol et al., 1979), conditions which may protect them from the effects of antimicrobials unable to enter cells or inactivated by low $\mathrm{pH}$. Thus, it is not surprising that for treating typhoid fever and chronic carriers of Salm. typhi certain antibiotics are ineffective despite good in-vitro activity (Hornick et al., 1970). Therefore, alternative methods for testing the susceptibility of Salm. typhi to antimicrobial agents are needed. Recently, we have shown that Salm. typhi is able to survive within human monocyte-derived macrophages (Vladoianu, Chang \& Pechère, 1990). Here we report on the in-vitro effects of ampicillin, ceftriaxone, chloramphenicol, pefloxacin and trimethoprim-sulphamethoxazole against Salm. typhi Ty2 when phagocytosed by human monocyte-derived macrophages.

-Corresponding author. 


\section{Bacteria}

\section{Materials and methods}

The virulent, smooth Ty2 strain of Salm. typhi Vi+, used by us in previous studies (Vladoianu et al., 1965, 1990), was cultured on Tryptone Soya agar (Oxoid Ltd., Basingstoke, UK) for $18 \mathrm{~h}$ at $37^{\circ} \mathrm{C}$. After opsonization with human normal serum ( $30 \mathrm{~min}, 37^{\circ} \mathrm{C}$ ) a suspension of the bacteria was made in medium 199 (M199; Seromed, Munich, FRG) supplemented with $10 \%$ heat-inactivated $\left(60 \mathrm{~min}, 56^{\circ} \mathrm{C}\right)$ normal serum, corresponding to a turbidity of 10 international opacity units/ml (WHO, 1954). From this suspension, a series of ten-fold dilutions was prepared in the same medium. One of these dilutions served as inoculum while others were used to count the viable bacterial cells as colony forming units (cfu) by a pour-plate technique.

\section{Antimicrobial agents and MIC determinations}

The antimicrobial agents used in this study were: ampicillin (Beecham Laboratories, Brentford, England), ceftriaxone (Hoffman La Roche and Co. Ltd, Basel, Switzerland), chloramphenicol (Calbiochem-Behring Corp.), trimethoprim-sulphamethoxazole (Lagap Pharma AG, Zug/Vezia, Switzerland), pefloxacin mesylate (Roger Bellon, Paris, France), and gentamicin (Seromed, Munich, FRG). All compounds were diluted in culture medium after being dissolved according to manufacturer's instructions.

The minimal inhibitory concentrations (MIC) of antimicrobials for Salm. typhi Ty2 were determined as previously described (Michéa-Hamzehpour et al., 1987).

\section{Preparation of human monocyte-derived macrophages}

Human monocyte-derived macrophages were obtained as previously described (Vladoianu et al., 1990). Human mononuclear cells were obtained from the blood of human volunteers serologically negative for hepatitis B, syphilis and HIV, and without a history of typhoid fever or vaccination against typhoid. Heparinized blood was overlaid on Ficoll-Paque (Pharmacia, Uppsala, Sweden) and centrifuged at $450 \mathrm{~g}$ for $30 \mathrm{~min}$. The purified mononuclear cells were dispensed into the wells of 96-well microtitre plates (Costar, Cambridge, MA, USA. After overnight incubation at $37^{\circ} \mathrm{C}$ the non-adherent cells were discarded by washing with prewarmed M199 and fresh M199 with $10 \%$ serum was added. The medium was replaced every three days and the monolayers were used after 12-14 days of incubation when the macrophages showed complete differentiation. The number of macrophages per well was approximately $10^{5}$ cells, as assessed by microscopy and by measuring the protein content of the wells against a previously constructed standard curve. Cell viability was always $>95 \%$ as tested by the trypan blue exclusion test (Boyse, Old \& Chouroulinkov, 1964). The phagocytic ability of macrophages was tested by their phagocytosis of heat-killed Candida albicans $\left(30 \mathrm{~min}, 100^{\circ} \mathrm{C}\right.$ ) (Smith \& Rommel, 1977).

\section{In-vitro assay of bacterial survival within macrophages}

This assay was performed as previously described (Vladoianu et al., 1990). After discarding the M199-10\% serum from the wells, adherent macrophage monolayers were infected with Salm. typhi Ty2 by adding $100 \mu \mathrm{l}$ of a suspension (in M199-10\% serum) containing approximately $9 \times 10^{6} \mathrm{cfu} / \mathrm{ml}$ Salm. typhi Ty2. The bacterial-cell 
ratio was $9: 1$. The cell monolayers were incubated for $1 \mathrm{~h}$ at $37^{\circ} \mathrm{C}$, the wells were then washed twice and some monolayers were lysed with $0.1 \%$ Triton $\mathrm{X}-100$ at $4^{\circ} \mathrm{C}$. Test wells received the antibiotics in M199-10\% serum at concentrations of one and ten times their previously determined extracellular MIC, and were incubated for $19 \mathrm{~h}$. Control wells included antibiotic-free wells and wells containing gentamicin, which is only active against extracellular Salm. typhi, at a concentration of $10 \mathrm{mg} /$; (the MIC of gentamicin for extracellular Salm. typhi Ty2 was $0.30 \mathrm{mg} / \mathrm{l}$ ). At the end of the incubation period, the wells were washed three times and the remaining cell monolayers were lysed with $0.1 \%$ Triton $\mathrm{X}-100$ at $4^{\circ} \mathrm{C}$. The cfu were counted from the lysed homogenates. The bacteria recovered from the lysed homogenates were tested for their antibiotic susceptibility in order to confirm that survival within monolayers was not the result of the development of antibiotic resistance.

\section{Toxicity controls and statistical tests}

Controls for the toxicity of the antimicrobials on human-monocyte derived macrophages were performed by using the trypan blue dye exclusion test (Boyse et al., 1964).

Data are reported as the mean $\pm S E M$. Significance was assessed by using Student's $t$-test; a $P$ value $<0-05$ was considered significant.

\section{Results}

MICs of antibiotics for extracellular Salm. typhi Ty2 were: ampicillin, $0.5 \mathrm{mg} / \mathrm{l}$; ceftriaxone, $0.1 \mathrm{mg} /$; chloramphenicol, $2.2 \mathrm{mg} /$; pefloxacin, $0.05 \mathrm{mg} / 1$; and trimethoprim-sulphamethoxazole, $0.05 / 0.25 \mathrm{mg} / \mathrm{l}$. The effects of antimicrobials against phagocytosed Salm. typhi Ty2, at one and ten times their respective MIC are shown in Figure 1. At $20 \mathrm{~h}$ after infection, control monolayers had a mean of $10^{4} \mathrm{cfu} / \mathrm{well}$. Control wells with gentamicin $(10 \mathrm{mg} / 1)$ yielded high bacterial counts indicating that in our experiments most or all the Salm. typhi recovered were intracellular. Ampicillin, ceftriaxone and peffoxacin showed good killing ( $<0.25 \log _{10} \mathrm{cfu} /$ well) at both one and ten times their MIC $(P<0.001$, compared with antibiotic-free controls). Chloramphenicol and trimethoprim-suphamethoxazole showed limited killing at the MIC ( $>2 \log _{10}$ to $<3 \log _{10}$ cfu/well). At ten times the MIC, trimethoprim-sulphamethoxazole showed good killing whereas chloramphenicol still remained bacteriostatic $\left(1.45 \log _{10} \mathrm{cfu} /\right.$ well). None of the antibiotics tested was toxic for the macrophage monolayers at the concentrations used, as shown by the trypan blue dye exclusion test (data not shown). The in-vitro susceptibility of extracellular bacteria and bacteria recovered from lysed macrophages was identical showing that the surviving bacteria had not acquired resistance after drug exposure.

\section{Discussion}

Ampicillin, ceftriaxone and pefloxacin, but not chloramphenicol, were clearly bactericidal against phagocytosed Salm. typhi Ty2. Trimethoprim-sulphamethoxazole was found to be bactericidal at ten times the MIC, but not at the MIC. The observation that gentamicin was ineffective against intracellular Salm. typhi despite a low extracellular MIC is in agreement with previous reports (Lissner, Swanson \& O'Brien, 1983; Vladoianu et al., 1990). The concentrations of antimicrobials used in our in-vitro assays 


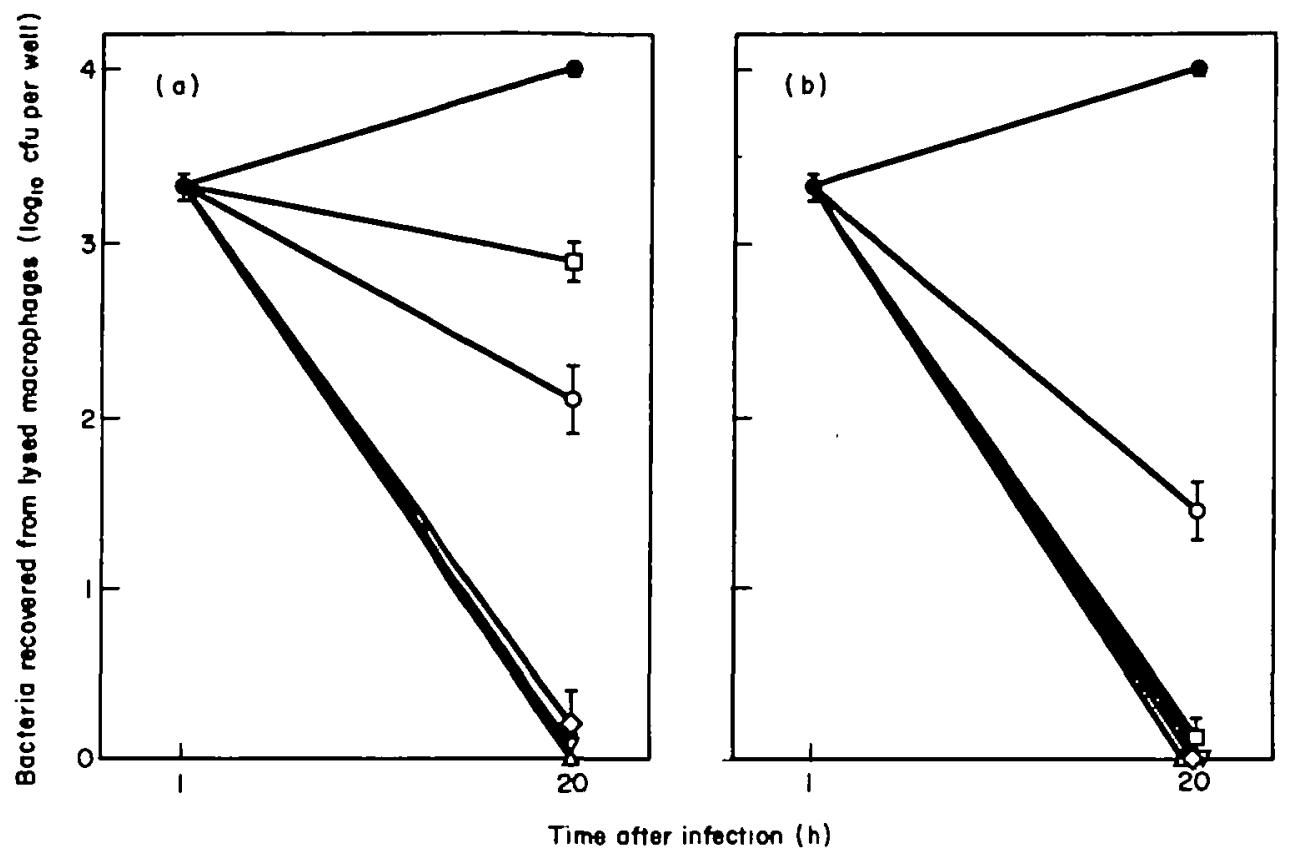

Flgure 1. Effects of antimicrobials on the survival of Salm. typhi Ty2 phagocytosed by human monocytederived macrophages as assessed by the number of bacteria recovered from lysed cells $\left(\log _{10} \mathrm{cfu} / \mathrm{well}\right)$. The bacteria-cell ratio was $9: 1$ ( $9 \times 10^{5} \mathrm{cfu} / 10^{3}$ cells). $\odot$, Controls; $\diamond$, ampicillin; $\nabla$, ceftriaxone; $O$, chloramphenicol; $\Delta$, pefloxacin; $\square$, trimethoprim-sulphamethoxazole. (a) Antimicrobials added at the MIC. (b) Antimicrobials added at 10 times the MIC. Results for each point represents the mean IS.E.M. of four wells.

are within achievable levels in the blood of patients treated with standard dosages of these compounds (Thornsberry \& Sabath, 1985).

Salm. typhi and other Salmonella spp. are susceptible to many antibiotics in vitro, but the in-vitro response correlates poorly with the in-vivo response (Hook, 1985). Salmonellae are bacteria capable of penetrating cells and multiplying within phagocytic cells (Carrol $e t$ al., 1979), and the discrepancy between the results of in-vitro tests and clinical findings may be due to the failure of some antibiotics to penetrate phagocytic cells adequately. Although the intracellular concentrations of the antimicrobials tested were not determined in the present study, our results suggest that all these compounds were able to penetrate macrophages. Chloramphenicol, trimethoprim and quinolones are known to penetrate phagocytic cells at different rates (Prokesch \& Hand, 1982; Easmon \& Crane, 1985; Koga, 1987; Hand \& King-Thompson, 1989). Penicillins and cephalosporins have the reputation of concentrating poorly in polymorphonuclear leucocytes (Prokesch \& Hand, 1982; Koga, 1987), hence possessing limited intracellular bioactivity (Vosbeck, James \& Zimmermann, 1984). However, our results showing the effects of ampicillin and ceftriaxone on intracellular Salm. typhi suggest that these compounds were able to enter human monocyte-derived macrophages. There is the possibility that these compounds entered human monocyte-derived macrophages by pinocytosis, as has been shown for cephalosporins where they are able to kill phagocytised Staphylococcus aureus when the killing mechanisms of the monocytes have been blocked (Van den Broek et al., 1986). Moreover, ceftriaxone has been shown to be concentrated within phagocytes in vivo (Kuhn, Angehrn \& Havas, 1986). Further 
studies using systems such as those described by us may help in the selection of compounds active against Salm. typhi within phagocytes.

Our results correlate well with the known clinical effect of antimicrobials in human Salm. typhi infection. Chloramphenicol has been regarded as the drug of choice for the treatment of typhoid fever (Hook, 1985). However, chloramphenicol therapy has a high relapse rate and is not effective in treating chronic enteric carriers (Hornick et al., 1970; Hook, 1985). Chloramphenicol did not exert a bactericidal effect on intraphagocytic Salm. typhi and probably therapy in vivo is not always able to eradicate the bacteria from the phagocytes completely. Trimethoprim-sulphamethoxazole has been used for the treatment of typhoid fever and for the treatment of chronic enteric carriers with variable results, ranging from equivalence to chloramphenicol to an unsatisfactory response (Hook, 1985). Among the factors causing this variability in results, administration of insufficient doses of trimethoprim-sulphamethoxazole has been postulated (Hook, 1985). Our results might support this observation because Salm. typhi was eradicated from human-monocyte derived macrophages only when they were exposed to the highest concentration tested. Ampicillin has been used for the treatment of typhoid fever and has been considered as the treatment of choice for chronic enteric carriers who have normally functioning gallbladders without evidence of cholelithiasis (Simon \& Miller, 1966; Phillips, 1971). Part of the efficacy of this antibiotic might be explained by the bactericidal effect of ampicillin on intracellular Salm. typhi. Third generation cephalosporins and quinolones have recently been used for the treatment of both typhoid fever and chronic enteric carriers and found to be useful for these indications (Bryan, Rocha \& Scheld, 1986; Soe \& Overturf, 1987; Murray, 1989; Waldvogel, 1989). Again, an important factor in the efficacy of these antibiotics is probably their good intracellular bioactivity. From an epidemiological viewpoint, since these antibiotics seem not to yield a temporary Salm. typhi carrier state, as observed with chloramphenicol, they may be playing a major role in blocking secondary transmission of Salm. typhi and thereby preventing outbreaks of typhoid fever (Bryan et al., 1986; Soe \& Overturf, 1987; Murray, 1989; Waldvogel, 1989).

In conclusion, the present studies may help to provide a rationale for the selection and administration of effective antimicrobials in the treatment of typhoid fever and chronic carriers of Salm. typhi.

\section{Acknowledgements}

This work was supported in part by grant $32-25800.88$ from the Swiss National Science Foundation and the Finanz Pool 3R Foundation.

\section{References}

Boyse, E. A., Old, L. J. \& Chouroulinkov, I. (1964). Cytotoxic test for demonstration of mouse antibody. Methads in Medical Research 10, 39-47.

Bryan, J. P., Rocha, H. \& Scheld, W. M. (1986). Problems in salmonellosis: rationale for clinical trials with newer $\beta$-lactam agents and quinolones. Reviews of Infectious Diseases 8, 189-207.

Carrol, M. E. W., Jackett, P. S., Aber, V. R. \& Lowrie, D. B. (1979). Phagolysosome formation, cyclic adenosine $3^{\prime}: 5^{\prime}$-monophosphate and the fate of Salmonella typhimurium within mouse peritoneal macrophages. Joumal of General Microbiology 110, $421-9$.

Easmon, C. S. F. \& Crane, J. P. (1985). Uptake of ciprofloxacin by human neutrophils. Joumal of Antimicrobial Chemotherapy 16, 67-73.

Edelman, R. \& Levine, M. M. (1986). Summary of an international workshop on typhoid fever. Reviews of Infectious Diseases 8, 329-49. 
Hand, W. L. \& King-Thompson, N. L. (1989). The entry of antibiotics into human monocytes. Journal of Antimicrobial Chemotherapy 23, 681-9.

Hook, E. W. (1985). Salmonella species (including typhoid fever). In Principles and Practice of Infectious Diseases, 2nd edn (Mandell, G. L., Douglas, R. G., \& Benneth, J. E., Eds), pp. 1256-69. John Wiley, New York.

Hornick, R. B., Greisman, S. E., Woodward, T. E., Dupont, H. L., Dawkins, A. T. \& Snyder, M. J. (1970). Typhoid fever: pathogenesis and immunologic control. New England Journal of Medicine 283, 686-91.

Koga, H. (1987). High-performance liquid chromatography measurement of antimicrobial concentrations in polymorphonuclear leukocytes. Antimicrobial Agents and Chemotherapy 31, 1904-8.

Kuhn, H., Angehrn, P. \& Havas, L. (1986). Autoradiographic evidence for penetration of ${ }^{3} \mathrm{H}$-cefriaxone (Rocephin) into cells of spleen, liver and kidney of mice. Chemotherapy (Basel) 32, 102-12.

Lissner, C. R., Swanson, R. N. \& O'Brien, A. D. (1983). Genetic control of the innate resistance of mice to Salmonella typhimurium: expression of the lty gene in peritoneal and splenic macrophages isolated in vitro. Journal of Immunology 131, 3006-13.

Michéa-Hamzehpour, M., Auckenthaler, R., Regamey, P. \& Pechère, J.-C. (1987). Resistance occurring after fluoroquinolone therapy of experimental Pseudomonas aeruginosa peritonitis. Antimicrobial Agents and Chemotherapy 31, 1803-8.

Murray, B. E. (1989). Quinolones and the gastrointestinal tract. European Journal of Clinical Microbiology and Infectious Diseases 8, 1093-102.

Phillips, W. E. (1971). Treatment of chronic typhoid carriers with ampicillin. Journal of the American Medical Association 217, 913-5.

Prokesch, R. C. \& Hand, W. L. (1982). Antibiotic entry into human polymorphonuclear leukocytes. Antimicrobial Agents and Chemotherapy 21, 373-80.

Simon, H. J. \& Miller, R. C. (1966). Ampicillin in the treatment of chronic typhoid carriers. Report on fifteen treated cases and a review of the literature. New England Journal of Medicine 274, 807-15.

Smith, D. L. \& Rommel, F. (1977). A rapid micro method for the simultaneous determination of phagocytic-microbiocidal activity of human peripheral blood leukocytes in vitro. Journal of Immunological Methods 17, 241-7.

Soe, G. B. \& Overturf, G. D. (1987). Treatment of typhoid fever and other systemic salmonelloses with cefotaxime, ceftriaxone, cefoperazone, and other newer cephalosporins. Reviews of Infectious Diseases 9, 719-36.

Thornsberry, C. \& Sabath, L. D. (1985). Approximate concentration of antimicrobial agents achieved in blood. In Manual of Clinical Microbiology, 4th edn (Lennette, E. H., Balows, A., Hausler, W. J. \& Shadomy, H. J., Eds), pp. 1021-2, American Society for Microbiology. Washington, DC.

Van den Broek, P. J., Buys, L. F. M., Mattie, H. \& van Furth, R. (1986). Comparison of the effect of phenoxymethylpenicillin, cloxacillin, and flucloxacillin on Staphylococcus aureus phagocytosed by human monocytes. Journal of Antimicrobial Chemotherapy 17, 767-74.

Vladoianu, I. R., Chang, H. R. \& Pechère, J.-C. (1990). Expression of host resistance to Salmonella typhi and Salmonella typhimurium: bacterial survival within macrophages of murine and human origin. Microbial Pathogenesis 8, 83-90.

Vlădoianu, I. R., Dimache, G., Antohi, S., Vlădoianu, C. \& Zarma, O. (1965). Laboratory tests on the effectiveness of oral vaccination of young children against typhoid and paratyphoid A and B. Bulletin of the World Health Organization 32, 37-45.

Vosbeck, K., James, P. R. \& Zimmermann, W. (1984). Antibiotic action on phagocytosed bacteria measured by a new method for determining viable bacteria. Antimicrobial Agents and Chemotherapy 25, 735-41.

Waldvogel, F. A. (1989). Clinical role of the quinolones today and in the future. European Journal of Microbiology and Infectious Diseases 8, 1075-9.

World Health Organization. (1954). Expert Committee on Biological Standardization. World Health Organization Technical Report Series 86, 14.

(Received 26 March 1990; accepted 2 July 1990) 